\title{
Morte: o difícil desfecho a ser comunicado pelos médicos
}

\section{Death: the hard denouement to be transmitted by the doctors}

\author{
Muerte: el difícil resultado a ser comunicado por los médicos \\ Daniela Trevisan Monteiro* \\ Universidade Federal do Rio Grande do Sul - UFRGS, Porto Alegre, Rio Grande do \\ Sul, Brasil
}

\section{Cristine Gabrielle da Costa dos Reis**}

Universidade Federal de Santa Maria - UFSM, Santa Maria, Rio Grande do Sul, Brasil

\author{
Alberto Manuel Quintana*** \\ Universidade Federal de Santa Maria - UFSM, Santa Maria, Rio Grande do Sul, Brasil

\section{Jussara Maria Rosa Mendes****} \\ Universidade Federal do Rio Grande do Sul - UFRGS, Porto Alegre, Rio Grande do \\ Sul, Brasil
}

\begin{abstract}
RESUMO
Este estudo traz resultados de uma pesquisa realizada com médicos de uma UTI adulto e teve como objetivo compreender, desde a perspectiva dos mesmos, o processo de comunicação de más notícias. Trata-se de uma pesquisa qualitativa, exploratória e descritiva, sobre a comunicação de más notícias na UTI, focando, mais precisamente, a comunicação da morte. A coleta dos dados foi realizada através de entrevistas semi-estruturadas e observação não-participante. Foram entrevistados 12 médicos que exercem atividade na UTI de um hospital escola do interior do Rio Grande do Sul. Para a análise de dados, foi utilizada a análise de conteúdo. Cumpriu-se com as recomendações éticas da Resolução 466/2012. Verificou-se que os médicos, geralmente, identificam a má notícia com a notícia de morte, considerada por eles como a mais difícil de ser comunicada. Há o sentimento de despreparo para comunicar más notícias, o que Ihes gera angústia. Considera-se que essa realidade poderá ser compartilhada com demais profissionais da equipe e acolhida por estes, desmistificando que a dor, o sofrimento e a morte do paciente estão ligados ao fracasso do médico. Com isso, permitir o emergir das emoções em um encontro genuíno e humano na relação com o paciente e familiar.

Palavras-chave: morte, comunicação de más notícias, psicologia da saúde.
\end{abstract}

\section{ABSTRACT}

This study shows the results of a survey performed with doctors in an adult ICU and aimed to understand, from their perspective, the process of communication of bad news. This is a qualitative, exploratory and 
descriptive research on the communication of bad news in the ICU, focusing more precisely on the communication of death. Data collection was conducted through semi-structured interviews and non-participant observation. We interviewed 12 physicians who practice activity in the ICU of a teaching hospital in the country region of Rio Grande do Sul. For data analysis, we used the content analysis. The ethical recommendations of Resolution 466/2012 were followed. It was found that doctors usually identify the bad news with the news of death, considered by them as the most difficult ones to be given. There is the feeling of unpreparedness to give bad news, which leads them to feel anguish. That reality can be shared with other professionals in the team and accepted by them, demystifying that the pain, suffering and death of the patient are connected to the failure of the doctor. Thus, allowing the emergence of emotions in a genuine and human encounter in the relationship with the patient and family.

Keywords: death, communication of bad news, health psychology.

\section{RESUMEN}

Este trabajo aporta resultados de una investigación realizada con médicos de una UTI y tuvo como objetivo comprender, desde la perspectiva de los mismos, el proceso de comunicación de malas noticias. Se trata de una investigación cualitativa, exploratoria y descriptiva, sobre la comunicación de malas noticias en UTI, focalizando principalmente la comunicación de la muerte. La recopilación de los datos fue realizada con entrevistas semiestructuradas y observación no-participante. Fueron entrevistados 12 médicos que ejercían actividad en UTI de un hospital escuela del interior del Rio Grande del Sur. Para el análisis de los datos fue utilizado el análisis de contenido. Se cumplieron con las recomendaciones éticas de la Resolución $466 / 2012$. Se verificó que los médicos, generalmente, identifican la mala noticia con la noticia de muerte, considerada por ellos la más difícil de ser comunicada. Existe el sentimiento de no estar preparado para comunicar malas noticias, lo que genera angustia. Se considera que esa realidad puede ser compartida con los demás profesionales del equipo y acogida por estos, desmitificando que el dolor, el sufrimiento y la muerte del paciente están vinculados al fracaso del médico. De esa forma permitir surgir las emociones en un encuentro genuino y humano con el paciente y su familiar.

Palabras-clave: muerte, comunicación de malas noticias, psicología de la salud.

\section{Introdução}

Ao falar em Unidade de Tratamento Intensivo (UTI), parece, sem dúvida, que o termo remete às doenças graves, à terminalidade e, consequentemente, à morte. Nesse contexto, as atitudes frente à morte foram mudando ao longo do tempo, até chegar a um interdito sobre esse assunto. Ariès (1977) descreve essa mudança clarificando que a morte era algo normal, muito simples, pois o homem sabia que iria morrer, seja porque percebeu ou porque foi advertido. A morte era uma cerimônia pública e organizada, onde o moribundo a presidia, cumprindo os últimos atos do cerimonial tradicional. Assim, até o século XIX e primeira metade do século XX (Chiavenato, 1998; Hennezel, 2006), morria-se em casa, no quarto, na cama e 
entre os familiares. Não era uma morte solitária e anônima, era uma morte pública, pois em determinada residência sabia-se que alguém iria morrer, porque o sacerdote se dirigia para lá, acompanhado por coroinhas em procissão. Dessa forma, o doente tinha consciência de sua morte, não era escondido dele a proximidade desta, ao contrário, ele era preparado para ela; a morte era aceita e natural.

Hoje, porém, a morte não é mais natural ou familiar. A partir de meados do século XX, a morte abandonou o meio familiar e passou a ser ocultada, considerada como um tabu incontestável e inaceitável, impensada e desprovida de sentido. Assim, a morte transformou-se em algo não natural e não familiar (Hennezel, 2006). A essa morte, Ariès (1977) chama-a de morte interdita.

Chiavenato (1998) aponta que, através da industrialização e a da urbanização, os doentes começaram a morrer nos hospitais, isolados da família e, por vezes, separados em quartos para doentes terminais, muitas vezes ligados a tubos e aparelhos, aguardando o momento em que o médico determina o desligamento das máquinas. Nesse sentido, Ariès (1977) afirma que se morre no hospital, porque esse proporciona os cuidados que não se pode dar em casa. Logo, o hospital também começa a ser considerado como um lugar privilegiado para a morte. Quanto a esse fato, Pitta (2003) define que, na Idade Média, a morte estava presente nas salas de visitas e, hoje, ela se esconde nos hospitais, em suas Unidades de Tratamento Intensivo.

Kübler-Ross (2008) destaca que quanto mais se avança na ciência, mais se teme e se nega a morte. Recorre-se a eufemismos sobre a morte, faz-se com que o morto pareça adormecido, manda-se as crianças saírem como forma de proteção ou, quando é no hospital, não se permite que as crianças visitem seus pais que se encontram à beira da morte. Há discussões sobre dizer ou não dizer a verdade para o paciente, o que raramente acontece quando o médico é da família e o paciente é atendido por ele desde seu nascimento até a morte.

Frente a essa mudança do lugar da morte, é importante ressaltar que, até o século XIV, a Igreja não permitia aos médicos atenderem os moribundos: eram os sacerdotes que os ajudavam a morrer. A morte era considerada como um desejo de Deus e não poderia ser impedida quando era anunciada. Era o padre que ficava ao lado da cama do doente enquanto o médico era expulso do quarto. Assim, foi apenas ao se estabelecer o conceito de morte, decorrente de causas naturais e que podem ser controladas pelo homem, que os médicos ganharam forças $e$, aos poucos, determinaram o momento do sacerdote trabalhar. A partir do século XVIII, os médicos assistem a morte, e os sacerdotes fazem papel de coadjuvantes. Essa nova hierarquia também é resultado do desenvolvimento da ciência médica. O conceito de morte natural prevaleceu quando a medicina 
encontrou novos métodos de tratamento e, frente a essas evidências, a Igreja não pode se contrapor (Chiavenato, 1998).

Porém, nessa luta, não é raro ver médicos que perdem o discernimento e realizam medidas surreais quando a morte já venceu a batalha, como afirma Kovács (2010). Isso pode acontecer porque os jovens médicos aprendem a prolongar a vida, mas recebem insuficiente treinamento ou esclarecimento sobre o que é vida. Fato que se reflete na fala taxativa de que não há mais o que fazer pelo paciente e, a partir daí, a atenção dos médicos é voltada apenas às máquinas e não à expressão facial do paciente, que pode transmitir informações mais eficazes do que os equipamentos (Kübler-Ross, 2008).

Esse modelo curativo, que diz respeito ao ensino e às práticas em saúde, enfrenta a barreira da finitude inexorável da vida - a morte (Figueiredo \& Jorge, 2009). A capacidade de cura da medicina está abaixo das probabilidades dos aparelhos de sobrevida. As tecnologias usadas nos hospitais mantêm os doentes vivos por longos períodos, porém sem a possibilidade de curá-los; apenas ampliou-se a agonia (Chiavenato, 1998). Nesse contexto, nos cursos de medicina, há uma dessensibilização dos subsídios que podem invocar a morte. As pessoas são transformadas em ossos, órgãos e sangue, numa reação contrafóbica, representando uma atitude de vitória e domínio. A objetividade científica é enfatizada aos estudantes, junto com o controle sobre a doença. Dessa forma, o medo da morte vira uma questão intelectual (Kovács, 2010). Com efeito, pode-se ressaltar que os estudantes de medicina são ensinados que esta é, primeiramente, um assunto de ciência e, depois, de pessoas. Os futuros médicos são treinados para investigar, diagnosticar, prolongar a vida e curar. Porém, quando entra em cena um paciente terminal, os médicos consideram que existe pouca coisa a fazer e sentem grande angústia frente à morte inevitável do seu paciente (Santos, 2009).

Complementando essa ideia, Menezes (2004) aponta que um dos grandes problemas do ensino e da prática médica do século XX é o distanciamento entre o cuidado ao paciente e a atenção aos seus órgãos e funções. A medicina do modelo moderno caracteriza-se pela fragmentação e objetificação da pessoa do doente. Há uma falta, nos cursos de medicina, de preparo do aluno para lidar com a morte; porém, na verdade, o ensino acadêmico prepara o aluno para lidar com essa problemática através do uso do mecanismo de negação. 0 isolamento das emoções, através do uso da neutralidade, faz com que os acadêmicos aprendam a vestir um manto imaginário que os proteja das emoções dos pacientes (Quintana, 2009).

Assim, a morte se transforma, no hospital, em fenômeno técnico causado pelo término dos cuidados - ela acontece de forma mais ou menos declarada por decisão do médico e da equipe hospitalar. $\mathrm{Na}$ maioria dos casos, o paciente já perdeu a consciência; dessa forma, a 
morte foi dividida, parcelada em etapas onde não se sabe qual a verdadeira morte: quando o indivíduo já perdeu a consciência ou quando parou sua respiração. São mortes silenciosas que substituíram e apagaram ação dramática da morte de antigamente (Ariès, 1977). Sobretudo, a configuração da morte, no hospital, implica uma mudança na sua representação; ela se desloca do âmbito sagrado e se inscreve na ação e eficácia técnica. Complementando esse pensamento, Ariès (1977) também ressalta o comportamento dos médicos enquanto donos da morte, de seu momento e de suas circunstâncias. Porém, os médicos esforçam-se para obterem de seus pacientes uma morte silenciosa, sem que este expresse seus sentimentos. Nesse sentido, há um consenso médico de um aceitável modo de comportamento dos pacientes frente à morte.

Destarte, no início da história humana, parafraseando Chiavenato (1998), a morte era frequente e não escandalizava. Foi preciso de 45 mil a 100 mil anos para individualizar a morte. Essa individualização pode ser o fato mais importante para o conceito atual de morte, pois é através dela que diversos acontecimentos se unem: o progresso da ciência e o recuo da Igreja em defender suas crenças. O que temos, então, aponta Ariès (1977), é o fato de que, durante a mudança do lugar de morrer, houve também o interdito da morte e, com isso, a inibição das reações do círculo médico e familiar. Pouco a pouco, a morte tomou outra forma, mais longínqua, dramática e tensa, tirando-a da consciência do homem.

Vários autores (Ariès, 1977; Chiavenato, 1998; Hennezel, 1999, 2006; Kovács, 2010; Kübler-Ross, 2008; Menezes, 2004; Pitta, 2003) realizam essa discussão sobre a morte e uma nova forma de se lidar com o paciente terminal vem sendo construída. Assim, esse tema tem ganhado forma e têm-se procurado modificar o discurso dos sentimentos suscitados pela morte. Porém, o interdito vai além do campo da saúde e, como colocado anteriormente, é um interdito social em que a ordem do discurso está intensamente alicerçada. Portanto, mesmo havendo novos meios de se fazer presente frente a um paciente terminal, a mudança ocorre a passos lentos; e a dificuldade de se falar da morte e permitir-se senti-la ainda existe fortemente.

Resultado disso é que, tanto para os médicos quanto para o hospital; a morte, é antes de tudo, um fracasso. É necessário, então, que ela deixe de mobilizar recursos e energias. Todavia, isso não significa que os profissionais de saúde, em sua rotina de trabalho, sejam insensíveis ao sofrimento e à morte (Menezes, 2004). O que acontece é que a maior parte dos hospitais são lugares onde se exerce uma competência técnica cada vez mais exigente; em que, geralmente, não podem ser abordadas questões relativas à vida íntima dos profissionais da saúde e de seus pacientes (Hennezel, 1999). 
Tem-se então que a morte é pouco abordada, tanto na sociedade em geral quanto no dialógico entre médicos e pacientes. Como consequência, a comunicação precária ou mesmo a falta de comunicação são os principais aspectos negativos do relacionamento profissional-paciente. Nesse contexto, a atitude médica depende de sua própria cultura e do seu preparo profissional (Moritz, 2005). No campo da saúde, a cultura científica é de renunciar a doença, o envelhecimento e a morte. Com efeito, são instituídas zonas de silenciamento sobre os limites dos tratamentos, seus efeitos adversos, a fragilidade da vida e a vulnerabilidade dos profissionais da saúde. Esses, provocados em suas competências e isolados em suas responsabilidades individuais, vivem esses limites com sentimentos de fracasso e impotência pessoal, sustentados a partir do âmbito privado de cada um (Penello \& Magalhães, 2010).

Em contrapartida, o prolongamento da vida e o avanço da medicina causaram um maior convívio com os processos de morrer, tanto para os familiares, quanto para os profissionais da área da saúde. A caricatura que melhor representa a morte é, justamente, a do ser humano que não pode morrer, com tubos por todas as partes do corpo e tendo ao lado ponteiros e ruídos de máquinas. Assim, o ser humano fica desapropriado de sua morte. Nesse momento, o que impera é o silêncio transformando em árdua a tarefa dos profissionais de saúde com seus pacientes. Logo, o convívio entre os pacientes, profissionais da saúde e família é prolongado, causando maior estresse para todos (Kovács, 2011).

Frente a isso, o Conselho Federal de Medicina (2012), considerando a atual relevância à questão da autonomia do paciente, atende a vontade do paciente terminal acerca de seu tratamento, como se registra no artigo 1 da Resolução 1995/2012, através de diretivas antecipadas manifestadas pelo paciente. Essa Resolução traz o chamado Testamento Vital. O que ocorre, segundo apontado pelo Conselho Federal de Medicina (2012), é o fato de que muitos pacientes, ao fim da vida, perdem a capacidade de comunicação. Para tanto, seria crucial que ele próprio pudesse decidir acerca de seus cuidados e tratamento antes de ficar impossibilitado disto. $O$ desejo do paciente, combinado com seu médico, fica acima de qualquer decisão familiar. O conselho ainda aponta, em pesquisas, que a maioria dos médicos acataria o desejo do paciente.

A Resolução traz, também, um importante avanço no que se refere à autonomia do paciente. Há, no entanto, algumas considerações a se fazer sobre este. A morte, como supracitada no decorrer do texto, é ainda um tabu em nossa sociedade. Além disso, quando recebido um diagnóstico de uma enfermidade grave ou estando já em um momento de fim da vida, o paciente passa por algumas fases, segundo Kübler-Ross (2008), como a negação e raiva. Tais sentimentos poderiam impossibilitar o paciente de assumir a 
proximidade de sua morte e, para tanto, esse não veria a importância de se fazer um Testamento vital. Também o termo Testamento infere a algo que se realiza pós-morte; o que, igualmente, poderia ser algo que fizesse com que pacientes se recusassem em fazê-lo. No entanto, essas são apenas algumas considerações que mereceriam que pesquisas fossem realizadas para confirmá-las ou refutá-las. O que é de fato verídico é o reconhecimento da autonomia do paciente frente a seu tratamento, o que envolve, igualmente, grandes mudanças na relação médico-paciente. Frente ao exposto, este estudo foi realizado com médicos e teve como objetivo compreender o processo de comunicação de más notícias no contexto de uma UTI para adultos, na perspectiva dos médicos.

\section{Método}

\subsection{Desenho do estudo}

O estudo proposto caracteriza-se como qualitativo (Minayo, 2010, de caráter exploratório e descritivo (Gil, 2010). Quanto à abordagem qualitativa, Turato (2005) pontua que essa busca a interpretação das relações de significado dos fenômenos, como atribuídos pelas pessoas. Assim, esse delineamento permite o aprofundamento dos significados que os sujeitos conferem as suas ações e relações.

\subsection{Participantes}

Participaram deste estudo 12 médicos que exercem atividade em Unidade de tratamento Intensivo (UTI) em um hospital escola do interior do Rio Grande do Sul. Desses, contam-se oito do sexo masculino e quatro do sexo feminino, com idades que variam de 26 a 56 anos. Foi incluída, nas entrevistas, a totalidade dos médicos atuantes na UTI onde se realizou a pesquisa.

\subsection{Técnicas e procedimentos de coleta de dados}

A coleta dos dados foi realizada através de entrevistas semiestruturadas e observação não-participante. De acordo com Minayo (2010), a entrevista não é apenas um trabalho de coleta de dados, ela sempre possui uma situação de interação onde as informações passadas pelos sujeitos podem ser afetadas através de suas relações com o entrevistador.

Os possíveis participantes foram abordados na própria UTI, através da mediação com o chefe desse setor. Inicialmente, foram esclarecidos sobre a temática e os objetivos do trabalho, riscos, benefícios e sigilo. Após, foi realizado o convite para a participação na 
pesquisa; posteriormente às explicações sobre a pesquisa. Quando aceito o convite, solicitou-se consentimento verbal e escrito, sendo que o Termo de Consentimento Livre e Esclarecido (TCLE) foi assinado por todos os participantes. Foi observado tanto o ambiente da UTI quanto o momento da comunicação entre médico e familiares. Para possibilitar a observação no momento da comunicação entre médico e familiares, esses igualmente receberam as explicações sobre a pesquisa e, quando aceita a participação, assinaram o TCLE.

As observações na UTI foram realizadas concomitantes às entrevistas e ocorreram por um período de 45 dias. Esse período demonstrou-se importante para a ambientação do pesquisador no local da coleta de dados, bem como por se considerar a necessidade do pesquisador tornar-se uma figura conhecida entre a equipe de saúde e familiares. Foram realizadas 14 observações no momento da comunicação entre médicos e familiares. Esse número ultrapassou o critério de saturação da amostra, de aplicabilidade prática, quando pouco de substancialmente novo é percebido (Fontanella, Ricas, \& Turato, 2008). Isso porque todas as comunicações entre médico-familiar foram observadas durante o período do trabalho em campo, para que não se induzisse, na UTI, o pensamento de que a pesquisa seria com pacientes com evolução negativa, podendo gerar desconforto entre os familiares.

\subsection{Procedimentos de análise dos dados}

As entrevistas foram analisas a partir da análise de conteúdo proposta por Bardin (2010) e Turato (2005). O que se propõe na formação das categorias posteriormente descritas é a condensação das representações contidas nas informações coletadas. Após a realização de um inventário, onde os elementos foram isolados e posteriormente classificados, sendo, a seguir, distribuídos e organizados segundo os critérios de repetição e relevância (Turato, 2003). No primeiro critério, foram arranjados em função de reincidências, considerando todas as emergentes do discurso do entrevistado. Já no segundo o que se priorizou foi a riqueza significativa do conteúdo e sua possibilidade de ser um elemento fundamental na articulação de sentido do discurso dos entrevistados.

Dessa forma, a operação de codificação possibilitou, através da exploração do material coletado, a sua transformação de dados brutos em dados trabalhados, reduzindo, assim, o volume de informações. Por fim, optou-se por em dividir os resultados em duas categorias: Comunicar a morte: más notícias para quem? e Morte: o interdito na comunicação. Pois, elas permitem a compreensão geral do estudo.

\subsection{Considerações e aspectos éticos}


A pesquisa foi realizada conforme as recomendações éticas da Resolução 466/2012 do Conselho Nacional de Saúde que normatiza as condições da pesquisa com seres humanos. Inicialmente, o projeto foi aprovado pelo comitê de ética e pesquisa da instituição em que foi realizada, sob o número CAAE (Certificado de Apresentação para Apreciação Ética): 0367.0.243.000-11, permitindo, assim, a coleta de dados. Para manter o anonimato dos participantes, os nomes dos médicos foram trocados pela letra $M$, seguida sistematicamente do número da entrevista; assim, apresentou-se como: M1, M2, M3, M4..., sucessivamente.

\section{Resultados e discussão}

Os resultados e discussão foram divididos em duas categorias para melhor visualização. São elas: Comunicar a morte: más notícias para quem? e Morte: o interdito na comunicação.

\subsection{Comunicar a morte: más notícias para quem?}

Esta categoria diz respeito às comunicações de morte contadas pelos médicos consideradas difíceis por eles. Ao contar suas experiências em relação às comunicações de más notícias nas quais os médicos consideraram impróprias, é de costume a utilização de frases na primeira pessoa, quando se refere aos prognósticos negativos, por exemplo: "Perdi o paciente (...). Eu perdi a perna [do paciente], mas eu salvei a vida" (M1).

Nota-se, nessa fala, tanto uma onipotência médica quanto a angústia da perda. O paciente teve uma perda (a sua perna) ou a família perdeu um ente querido (o paciente), porém o médico toma para si a perda na luta contra a doença ou a morte. Isso se concretiza na seguinte fala quando da morte de um paciente: "... eu representava uma esperança muito grande e ali eu me senti um fracassado" (M1). Esses sentimentos podem prejudicar na comunicação da notícia para a família, pois se o próprio médico vê a morte como um fracasso, como dizer para a família que o percurso naquela situação seria inevitavelmente a morte? O relato a seguir demonstra o quanto foi difícil para o médico lidar com essa situação:

...durante o processo de reanimação eu ouvia os gritos da esposa dele do lado de fora e eu estava fazendo uma reanimação cardíaca e ouvindo os gritos de desespero dela (...) $E$ eu tive que, depois de 45 minutos de tentativas, sem sucesso, de ressuscitação, sair para fora e dizer que ele tinha 
morrido. Eu acho que foi a, ...a, ... a comunicação mais difícil que eu já tive...(M1).

Percebe-se a luta obstinada contra a morte, através de 45 minutos de tentativa de reanimação, bem como, o quanto a reação emocional da família interfere na comunicação da má notícia. Como observa Quintana (2009), o melhor para a equipe de saúde é que o paciente ou sua família não expressem emoções de maneira excessiva. O ideal para o médico seria conversar sobre a doença, o tratamento e a impossibilidade de cura, sem ter que enfrentar as reações emocionais do paciente e sua família. No entanto, o médico sente-se despreparado para uma situação destas e mesmo quando possui um conhecimento teórico e prático sobre o assunto, não sabe qual seria a melhor maneira de comunicar, como se pode observar nos depoimentos a seguir:

Eu não tive outra forma de comunicar sem ser dizer: perdemos a vida (M1).

Porque a gente, às vezes, é muito técnico. Às vezes, a gente é muito frio, a gente não tem as palavras certas, ideais, para dizer no momento (M9)

E nunca ninguém falou até onde eu posso me envolver e até onde não (...) (M12)

A própria profissão médica, com visão positivista e onde se busca incansavelmente a cura, não prepara o médico para as situações de morte, pois "perder vidas", só se aprende através da experiência. Nos currículos da medicina, a busca ainda é sempre a cura, o que pode fazer com que muitos outros médicos se sintam fracassados quando a cura já não é mais possível. A formação médica, no que se refere ao contexto de morte, é considerada imprópria pelos próprios médicos e, segundo Junior, Rolim e Morrone (2005), tal formação deveria ser mais humanística e filosófica nas faculdades, para que, dessa forma, o profissional pudesse assumir uma postura de segurança e delicadeza para amparar os que perderam seus entes queridos.

Na pesquisa sobre a comunicação da morte, realizada em instituições de saúde, os achados demonstraram que é papel do médico, e não da equipe, falar sobre a morte com pacientes e familiares. Em contrapartida, os médicos não se sentem preparados para falar sobre morte, sendo que esse tema é visto como tarefa de ninguém, pois a função dos profissionais da saúde é manter a vida (Kóvacs, 2011)."... eu tinha uma expectativa lá em cima de que eu ia conseguir salvar aquele caso, de que eu era capaz de resolver, e aí tu levas uma rasteira da profissão medicina" (M1). 
Outro entrevistado também traz como exemplo de comunicação de más notícias uma situação de morte de uma adolescente de 15 anos, em que ele teria que realizar a comunicação para o pai desta. O médico explica que "Daí quando eu saí pela porta, só tinha uma saída e eu sabia que esse pai estaria lá" (M2).

Ou seja, percebe-se na fala que o médico não gostaria de comunicar para um pai a morte de sua filha. Como aponta Moritz (2007), o médico distancia-se daqueles que tanto necessitam para que não sinta, junto dos familiares, a dor da perda. Quando questionado se ele sairia por outra saída caso existisse, ele responde que: "Eu acho que a tentação seria grande. Porque não é fácil dizer para um pai que perdeu uma filha de 15 anos. E na verdade eu tinha ido ali para ajudar a colega e caí num pepino" (M2).

Há duas situações que podem ser pensadas nessa fala. A primeira é o fato de o médico sentir dificuldades em comunicar a morte de um paciente tão jovem para um pai, onde se pode inferir a existência de um processo de identificação. A segunda é o fato de que a percepção da perda de um paciente é conceituada como um "pepino". Caso o médico tivesse conseguido reanimar a paciente, isso poderia ser percebido como um ganho tanto em relação à profissão, quanto pessoal; porém, ao não ter êxito, a ajuda que ele foi prestar ao colega foi percebida como um "pepino", pois além da paciente ter morrido, o médico ainda teria que comunicar ao pai a morte de sua filha. Tal comunicação Ihe gerou tamanha angústia, que a maneira como ele se expressou durante a comunicação não deixou claro para - pai que a filha tinha morrido, gerando, por um momento, expectativa nesse pai de que o desfecho tinha sido positivo, como se percebe na fala do médico:

Daí, quando tu chegas assim, tu não tem o que dizer. Daí, eu perguntei o que aconteceu com a menina, se ele sabia o diagnóstico, se ele sabia isto, e não sei o que, ...aí disse que me chamaram para ajudar aqui, daí eu cheguei, aconteceu isto, aconteceu aquilo, e não sei o que. Mas, daí a impressão que se tem é que eles ficam entretidos com a história que tu vai contando, assim, parece que não cai a ficha... É, que vai dar tudo bem. Ahh, que no final, que eu fiz um diagnóstico brilhante. Infelizmente sua filha faleceu (M2).

Pensa-se na fala que o próprio médico precisa dessa conversa anterior como forma de elaboração da maneira como ele vai comunicar a morte. Havendo uma "história" anterior à comunicação propriamente dita: - sua filha faleceu. Essa situação também revela a dificuldade de lidar com as reações devido à perda, bem como o fato de que a evolução natural não é um pai perder um filho, e sim que a morte seria resultante da idade avançada. Dessa forma, a 
esperança/expectativa do médico é que o pai saiba o desfecho sem que ele precise de fato comunicar. Esses fatores são expressos em outros exemplos:

... os casos que eu tive, assim, mais estressantes, foram sempre os pais com os filhos, (...) eu me lembro que eu, ... de uma cena que me marcou muito, foi uma vez me chamaram para constatar um óbito. Daí a gente pergunta: "É constatação de óbito? O paciente é terminal?" (...) Ah, era um senhor que devia ter quase oitenta anos, ele estava sozinho com o filho, que recém tinha falecido, chorando desesperadamente, $e$ estava arrumando a malinha porque ele ia embora com o filho. Então, foi uma cena que me marcou muito, que foi o pai enterrar o filho, que não é uma coisa natural. Então, é uma coisa que sempre mais marca, é quando uma criança morre, ou um adulto jovem (M2).

As notícias mais ruins de dar, são de morte encefálica. (...) Porque geralmente é uma questão de trauma. É uma questão de um acidente. Não eram pessoas que já eram doentes, mas, pessoas que se acidentaram, tiveram um acidente de carro, de trânsito, são pacientes jovens. Não são pacientes no fim da vida, não é um paciente que fumou a vida inteira e agora teve uma pneumonia e um enfisema. Não, são pacientes que não tinham nada, que eram saudáveis, e, de repente a vida deles se modificou e acabou evoluindo para o óbito, assim, o resto do organismo funciona, o problema é só a cabeça. Então, este, ...que as pessoas não estão preparadas e nem capacitadas, ..., de repente tu fala para o filho que o pai idoso morreu, e outra coisa é dizer para um pai que o seu filho jovem, de seus vinte e trinta e poucos anos faleceu, é muito mais difícil. A aceitação é muito mais difícil (M3).

As falas anteriores reforçam a crença de que a morte deve ocorrer ao fim da vida, quando se tem mais idade e já viveu o suficiente. É aceitável um filho perder um pai, pois faria parte da ordem natural dos acontecimentos; porém um pai perder um filho é difícil de aceitar. Essa dificuldade deve ser pensada tanto em relação à perda do pai, quanto ao próprio médico, que aceita perder uma vida ao fim da vida, mas não aceita perder um paciente jovem. Segundo Junior et al. (2005), os casos que apresentam maior dificuldade de serem comunicados são, de fato, os de pacientes jovens ou de casos agudos. Segundo os autores, estes exigem um melhor relacionamento do profissional com a família, embora isso nem sempre aconteça. 
O entrevistado M3, assim como em sua fala anterior, traz como exemplo de comunicação que considerou difícil um prognóstico de morte encefálica. Essa dificuldade pode ser interpretada pelo fato de que, apesar de haver respaldo ético e bioético para a retirada de terapêutica nessas situações, o médico não possui respaldo jurídico, ficando muitas vezes a cargo da decisão da família sobre a retirada da terapêutica. Essa é uma das consequências do aperfeiçoamento tecnológico, segundo Moritz (2007), ou seja, a tomada de decisões diante da morte e do morrer. Com isso, a autora aponta para a importância de haver uma harmonia entre a equipe de profissionais que trabalham na UTI, os pacientes e seus familiares.

Ainda, quando há morte encefálica, entra a questão da doação de órgãos. Então, além de comunicar a morte, o médico precisa informar-se sobre o desejo da doação para poder manter ou retirar a terapêutica, bem como para entrar em contato com a equipe de captação de órgãos. O exemplo a seguir mostra claramente a comunicação do médico sobre a morte encefálica de um paciente:

... quando teve uma morte encefálica, foi uma paciente que deu óbito dentro da UTI, então o residente não sabia como abordar. Então eu disse, não, vamos lá, se você tem problema, não sabe como fazer, então eu vou aí e converso. Vamos respaldados com todos os dados que a gente tem, os exames clínicos e o exame radiológico que confirmou a morte encefálica, vamos comunicar aos familiares que saiu $o$ resultado do exame cerebral e a gente chamou a família para conversar... Chamei eles e disse: olha, infelizmente o exame que a gente fez para confirmar a morte encefálica, né, não existe fluxo, ou seja, confirmou que o cérebro está morto, então não há mais nada que a gente possa fazer agora, pelo, ..., melhor não dizer o nome, pela paciente em questão, então,..., tenho fazer uma pergunta, sei que é difícil neste momento, não sei se vocês,... se quiserem um tempo para pensar, podem pensar, mas, eu preciso saber se vocês são a favor ou não da doação dos órgãos dela. Podem pensar, se quiserem, fica na responsabilidade de vocês (M3).

Percebe-se na fala que na situação de morte encefálica o médico precisa ir respaldado com todos os dados que possui sobre 0 prognóstico. Além disso, muitas vezes a equipe de captação de órgãos demora a chegar, como informou o entrevistado, o que aumentaria o desgaste pela situação tanto para o médico quanto para os familiares.

Outro ponto interessante quanto aos exemplos que os médicos trouxeram é o fato de que foi pedido que eles falassem sobre alguma comunicação de más notícias que não foi considerada por eles como 
positiva, e todos os médicos trouxeram exemplos relacionados a óbitos de pacientes. Isso revela o quanto a má notícia é ligada com a morte, e o quanto o médico possui dificuldade em lidar com a morte, pois essa pode remeter a sua própria finitude.

Além disso, no contato da iminência da finitude, outra grande dificuldade que o profissional enfrenta é, não só de comunicar, mas também de ouvir as comunicações dos pacientes, sem se deixar impactar e paralisar. É preciso partir do pressuposto que, de alguma forma, alguns sujeitos sabem que estão morrendo e, por isso, precisam de ajuda para entender o que se passa consigo (Oliveira, Santos, \& Mastropietro, 2010). Entende-se que é aterrorizante para o médico ter que suportar a consciência de finitude do outro, uma vez que o remete a sua própria mortalidade. Como se percebe nas falas a seguir:

...eu não consigo ficar vendo muito depois que eu falo, continuamente, compreendo o sofrimento da família, não é. Que aí é muito duro, a família vai ter que fazer o seu luto, mas eu não tenho como, ... eu não fico acompanhando isto, né, ...(M7)

E a parte mais desagradável é quando tu tens que passar uma informação ruim. Uma notícia ruim. Olha o paciente piorou, o paciente vai precisar de um procedimento de risco e o paciente está em uma infecção grave, está piorando, tem chance de morrer, não vai recuperar. Aí a coisa é mais tensa, e tu tens que lidar com a reação destes familiares, em relação a estas informações. (M5).

Segundo Oliveira, Santos e Mastropietro (2010), o processo de escuta e presença, conforto e consolo, de forma não invasiva, mas acolhedora, auxilia na transformação psíquica dessa experiência dolorosa de iminência da morte. No entanto, percebe-se o quanto a angústia frente à morte influencia na qualidade da comunicação, uma vez que há uma negação maciça da finitude e uma dificuldade de aceitação. Dessa forma, os médicos acabam por se distanciar ainda mais dos pacientes e familiares, de modo a não entrar em contato com a morte, fato que agrava a situação de dor, tanto para o emissor da notícia, quanto para os receptores.

\subsection{Morte: o interdito na comunicação}

Embora a morte esteja próxima e que faça parte do cotidiano dos médicos, Kovács (2005) aponta para o grave distúrbio da comunicação que ocorre, chamado conspiração do silêncio, ou seja, profissionais da saúde que se empenham numa luta de vida ou morte 
e, diante do seu sentimento de fracasso, não sabem o que, nem como falar aos seus pacientes e familiares sobre o porquê da não melhora e da proximidade da morte. Devido à grande dificuldade apontada pelos médicos sobre a comunicação da morte de um paciente, essa categoria faz-se pela palavra não dita - a morte, substituída por diferentes denominações. Como fica ilustrado nas falas a seguir:

...não vai ter o que segurar ele. (...) Eu acho que nós estamos perdendo a guerra (M2)

...apesar do quadro dele ainda ser grave, existe risco de vida (M4)

O quadro dele é extremamente grave, a gente quase não tem expectativa de que ele saia da UTI (M3)

É importante analisar essas três falas separadamente, pois cada uma delas traz um aspecto diferente. Na primeira, o médico se refere à guerra. Seria essa a luta obstinada contra a doença? Se o médico comunica dessa forma, é porque ele se sentiu derrotado, pois perdeu a luta. Essa sensação de fracasso viria da própria visão da medicina onde se deve buscar a cura a qualquer custo, mesmo quando essa inexiste e a doença já é avançada. Na segunda comunicação, o médico fala sobre risco de vida, excluindo completamente a palavra morte, pois o paciente tem risco de morrer e não de viver. Na última fala, o médico relata que não possui expectativa de que ele saia da UTI. Porém, mesmo que o paciente morra ele vai sair da UTI, logo, nessa fala, também há a negação maciça da morte.

Tais atitudes como uso de eufemismos ou a troca da palavra morte por outras denominações podem ser atribuídas também à recusa do homem a pensar, naturalmente, sobre a inevitabilidade da finitude, tendo em vista que a morte, atualmente, é permeada de preconceitos e estigmas e uma série de elementos persecutórios que 0 amedrontam. Porém, quando os médicos são postos diante de um diagnóstico de uma doença fatal, confrontam-se com a fragilidade e iminência da terminalidade (Oliveira et al., 2010). De alguma forma, diante da finitude e de não saber como lidar com ela, os médicos passam a tentativa de excluir a palavra morte de suas comunicações e rotinas, uma vez que estão a todo o momento a substituindo por outras.

Deve-se explanar ainda que muitos médicos relataram que, quando a morte é esperada, a comunicação dessa não traria problemas. Porém, não foi o que se observou: mesmo que a morte seja esperada, como nas comunicações expostas, o médico sente dificuldades em comunicar; mudando seu tom de voz, falando pausadamente e não 
utilizando a palavra morte. Se os próprios médicos negam a morte, que é sua rotina diária dentro do hospital, por que então os familiares não haveriam de negar?

Sem dúvida, é inevitável pensar que a atitude dos profissionais significa, entre outras coisas, uma negação da morte, para que se possa se defender da finitude. Negar a morte é, então, uma das formas de não entrar em contato com essas experiências dolorosas. O ser humano cria uma camada de proteção que esconde uma fragilidade interna, a finitude e a vulnerabilidade (Kovács, 2005).

Para que o médico possa então, fazer o difícil processo de comunicação de uma forma mais adequada é preciso que ele tenha consciência de seus limites curativos e possa aprender a tratar 0 sujeito durante o processo de morrer, dessa forma, estando mais seguro para falar sobre a morte com os envolvidos. Essa fala, além disso, deve ser feita de forma honesta e humana, entendendo também o tempo de cada um de processamento dessas informações. É importante que essa comunicação seja feita por um médico preparado não apenas tecnicamente, mas eticamente e que, de preferência, esse profissional seja o mesmo durante o processo de constante informação e comunicação (Moritz, 2007). A relação contínua médico/paciente colabora na melhoria da qualidade do serviço de saúde, em contrapartida a rotatividade de profissionais no atendimento, o que muitas vezes ocorre enquanto um problema institucional, dificulta na humanização do atendimento. A continuidade do vínculo permite ao médico conhecer melhor a história do paciente e de sua família (Buetow, 1995), e a realizar um atendimento mais humanizado. Como se pode perceber em outra fala:

Que o ideal é você ter um vínculo bom, também, com a família. (...) Tu não sabe qual é a expectativa do familiar, não sabe se eles estão achando, ah, ele já sofreu demais, e, chegou o fim da linha. Ou se eles estão com muita expectativa no caso. Se eles estão aceitando bem a notícia ou não. Então, isto torna a comunicação da notícia ruim, aqui na UTI, muito difícil. $\mathrm{Na}$ minha opinião, acho que a gente não consegue fazer, passar uma notícia da forma ideal. Né, tem aquele problema de não criar vínculo, de não conhecer a família e não ter um seguimento mais longitudinal assim. (M11)

A comunicação a qual o médico deve atentar, sem dúvida, é também para a comunicação não-verbal. Desde um olhar atento para o paciente, à receptividade, confiança e intencionalidade. É preciso criar um espaço de confiança, respeitar as singularidades, perceber 0 outro, traduzir o que ele sente e ajudá-lo nesse processo, perceber as comunicações não verbais do paciente, decodificá-lo, tornando-o 
singularizado e valorizado. São aspectos que vão muito além de um aparato técnico e que favorecem a troca de informações e o andamento de todo o processo de morte e morrer (Bax \& Araújo, 2012).

\section{Considerações finais}

A morte ainda é interdita dentro de um discurso social. Transformada em tabu vive-se na ilusão da imortalidade. Por esse motivo, depararse com a morte do outro é tão difícil, pois remete à morte de si. Por isso, viver a morte como rotina quase que diária traz tanto sofrimento. Esse é negado, escondido e silenciado. Diante da maciça negação da morte e a interdição da mesma, entende-se o quanto se torna difícil demandar um olhar ao paciente moribundo e comunicar a morte e o morrer para seus entes queridos. Comunicar a morte é comunicar algo que, inevitavelmente, trará sofrimento a outro e, consequentemente, a quem a comunica. Por isso, a sensação de fracasso e impotência frente a todas as tecnologias da medicina. Por isso, a utilização maciça de mecanismos de defesa. Possivelmente, por esse motivo, apresenta-se tão difícil um cuidado próximo ao paciente, a valorização da sua singularidade e o estabelecimento de um espaço de confiança, uma vez que há uma barreia primordial que separa o profissional do paciente. Essa barreira, que se constitui pela negação, mostra-se espessa para que o médico não entre em contato com a morte e, consequentemente, não entre em contato real com o paciente e seus familiares.

Sendo assim, a comunicação torna-se ainda mais difícil, uma vez que há a negação da morte e a interdição da própria palavra, sendo necessário substituí-la por outras, o que, muitas vezes, dificulta o entendimento da informação a ser passada. A exclusão da palavra morte apresenta-se como mais uma tentativa de não reconhecimento da finitude. Falar na mesma, olhar para o paciente de forma singular e reconhecer a eminência de morte, faz com o que os médicos se confrontem com uma imensa angústia e proximidade de sua própria finitude. Dessa forma, não sabendo como lidar, substituem a palavra morte de forma a continuar a negar a terminalidade.

Então, não se trata de alocar disciplinas sobre a morte no decorrer do curso de medicina. Não se trata de fazer cursos que ensinem a como lidar com estas situações. Trata-se de um lidar com a morte e o morrer de forma menos velada. Busca-se, com isso, um profissional mais crítico e reflexivo. Ciente de que há um sofrimento na vivência hospitalar, realidade esta que poderá ser compartilhada com demais profissionais da equipe e acolhida por estes; desmistificando, assim, que a dor, o sofrimento e a morte do paciente estão ligados ao fracasso do médico. 
Ter-se-ia, nesse sentido, um profissional apto a pensar sobre a relação médico/paciente e a desenvolver estratégias que permitam construir outras possibilidades em torno da morte que comporte uma maior capacidade de viver em relação a esta e consigo mesmo em seu ambiente de trabalho, diminuindo o sofrimento e possibilitando outras interfaces que priorizem um atendimento mais humanizado. Trata-se de permitir o emergir das emoções em um encontro sincero na relação com o paciente e familiar. Busca-se não mais colocar a morte em lugar escamoteado dentro do hospital e sim permitir falar sobre ela. Todos morrem. E viver nessa consciência é permitir ao médico que este ofereça um cuidado ao outro mais próximo. E a si, mais sincero.

\section{Referências}

Ariès, P. (1977). História da morte no ocidente: da idade média aos nossos dias. Rio de Janeiro: Francisco Alves.

Bardin, L.(2010). Análise de conteúdo. Lisboa: Edições 70.

Bax, A. M. C., \& Araújo, S. T. C. de. (2012). Expressão não verbal do paciente no cuidado: percepção do enfermeiro em unidade cardiointensiva. Escola Anna Nery, 16(4), 728-733. Recuperado em 14 junho, 2012, de http://www.scielo.br/scielo.php?script=sci_arttext\&pid=S1414$81452012000400012 \& \operatorname{lng}=$ en\&tIng=pt.

10.1590/S141481452012000400012

Brasil (2012). Conselho Nacional de Saúde. Resolução No 466/2012. Sobre pesquisa envolvendo seres humanos. Brasília: Conselho Nacional de Saúde.

Buetow, S. (1995). What do general practioners and their patients want from general practice and are they receiving it? A framework. Social Science and Medicine, 40, 213-221.

Chiavenato, J. J. (1998). A morte: uma abordagem sociocultural. São Paulo: Moderna.

Conselho Federal de Medicina. (2012). Resolução CFM no 1.995/2012. Publicada no D.O.U. de 31 de agosto de 2012, Seção I, p.269-70.

Figueiredo, M. G. M., \& Jorge, M. M. (2009). Cuidados paliativos e bioética. In: M. G. M. Figueiredo, \& M.T Figueiredo. (Orgs.). Cuidados paliativos e tanatologia: coletânea de textos. São Paulo.

Fontanella, B. J. B., Ricas, J., \& Turato, E. R. (2008). Amostragem por saturação em pesquisas qualitativas em saúde: contribuições teóricas. Cadernos de Saúde Pública, 24(1), 1727. Recuperado em 17 abril, 2011, de http://www.scielosp.org/pdf/csp/v24n1/02.pdf 
Gil, A. C.(2010). Como elaborar um projeto de pesquisa. 5a ed. São Paulo: Atlas.

Hennezel, M. (1999). A arte de morrer: tradições religiosas e espiritualidade humanista diante da morte na atualidade. Petrópolis: Vozes.

Hennezel, M.(2006). A morte no centro da vida. In: M. Hennezel (Org.). Morrer de olhos abertos (pp. 55-73). Portugal: Casa das Letras.

Júnior, A. S., Rolim, L. C., \& Morrone, L. C. (2005). O preparo do médico e a comunicação com familiares sobre a morte. Revista da Associação Médica Brasileira, 51(1), 11-16. Recuperado em 10 julho, 2013, de http://www.scielo.br/scielo.php?script=sci_arttext\&pid=S010442302005000100013\&lng=en\&tIng=pt. 10.1590/S010442302005000100013.

Kovács, M. J. (2005). Educação para a morte. Psicologia: Ciência e Profissão, 25(3), 484-497. Recuperado em 21 julho, 2013, de http://www.scielo.br/scielo.php?script=sci_arttext\&pid=S14149 $8932005000300012 \& \operatorname{lng}=$ en\&tlng $=\mathrm{pt}$

Kóvacs, M. J. (2010). Morte e desenvolvimento humano. São Paulo: Casa do Psicólogo.

Kóvacs, M. J. (2011). Instituições de Saúde e a Morte. Do Interdito à Comunicação. Psicologia: ciência e profissão, 31 (3), 482-503.

Kübler-Ross, E. (2008). Sobre a morte e o morrer: O que os doentes terminais têm para ensinar a médicos, enfermeiras, religiosos e aos seus próprios parentes (9a ed.). São Paulo: Martins Fontes.

Menezes, R. A. (2004). Em busca da boa morte: antropologia dos cuidados paliativos. Rio de Janeiro: Garamond.

Minayo, M. C. de S. (2010). O desafio do conhecimento: pesquisa qualitativa em saúde. São Paulo: Hucitec. (Obra original publicada em 1992).

Moritz, R. A. (2005). Os profissionais de saúde diante da morte e do morrer. Bioética, 13(2), 51-63. Recuperado em 2 julho, 2011, de:

http://revistabioetica.cfm.org.br/index.php/revista_bioetica/arti cle/view/107/112

Moritz, R. D. (2007). Como melhorar a comunicação e prevenir conflitos nas situações de terminalidade na Unidade de Terapia Intensiva. Revista Brasileira de Terapia Intensiva, 19(4), 485489. Recuperado em: 21 julho, 2013, de: http://www.scielo.br/scielo.php?script=sci_arttext\&pid=S01035 07X2007000400014\&lng=en\&tlng=pt. 10.1590/S0103$507 \times 2007000400014$

Oliveira, E. A. de, Santos, M. A. dos, \& Mastopietro, A. P. (2010). Apoio psicológico na terminalidade: ensinamentos para a vida. Psicologia em Estudo, 15(2). Recuperado em: 21 julho, 2013, 
de:

http://www.scielo.br/scielo.php?script=sci_arttext\&pid=S1413$73722010000200002 \&$ Ing $=$ en\&nrm =iso

Pitta, A. (2003). Hospital: dor e morte como ofício (5a ed.). São Paulo: Annablume.

Penello, L., \& Magalhães, P. (2010). Comunicação de más notícias: Uma questão se apresenta. In Instituto Nacional de Câncer. Coordenação Geral de Gestão Assistencial. Coordenação de Educação. Comunicação de notícias difíceis: Compartilhando desafios na atenção à saúde (pp. 23-26). Rio de Janeiro: INCA.

Quintana, A. M. (2009). Morte e formação médica: é possível a humanização? In: F.S. Santos (Org.). A arte de morrer: visões plurais (Vol. 2.). São Paulo: Comenius.

Santos, F. S. (2009). Tanatologia: a ciência da educação para a vida. In: F.S. Santos (Org.). A arte de morrer: visões plurais (Vol. 2.). São Paulo: Comenius.

Turato, E. R. (2003). Tratado da metodologia da pesquisa clínicoqualitativa: construção teórico-epistemológica, discussão comparada e aplicação nas áreas da saúde e humanas. Petrópolis: Vozes.

Turato, E. R. (2005). Métodos qualitativos e quantitativos na área da saúde: definições, diferenças e seus objetos de pesquisa. Revista de Saúde Pública, 39 (3), 507-14. Recuperado em 14 abril, 2011, de: http://www.scielo.br/pdf/rsp/v39n3/24808.pdf

\section{Endereço para correspondência \\ Daniela Trevisan Monteiro}

Universidade Federal do Rio Grande do Sul

Instituto de Psicologia

Rua Ramiro Barcelos, 2600, $4^{\circ}$ andar, sala 413 A, Santa Cecília, CEP 90035-003, Porto Alegre - RS, Brasil

Endereço eletrônico: daniela.trevisan.monteiro@gmail.com

Cristine Gabrielle da Costa dos Reis

Universidade Federal de Santa Maria

Campus Universitário

Avenida Roraima, 1000, Predio 74B sala 3212a, Camobi, CEP 97105-900, Santa Maria - RS, Brasil

Endereço eletrônico: cristinecostareis@hotmail.com

\section{Alberto Manuel Quintana}

Universidade Federal de Santa Maria

Campus Universitário

Avenida Roraima, 1000, Predio 74B sala 3212a, Camobi, CEP 97105-900, Santa Maria - RS, Brasil

Endereço eletrônico: albertom.quintana@gmail.com

\section{Jussara Maria Rosa Mendes}

Universidade Federal do Rio Grande do Sul

Instituto de Psicologia

Ramiro Barcelos, 2600, $4^{\circ}$ andar, sala 413 A, Santa Cecília, CEP 90035-003, Porto Alegre - RS, Brasil

Endereço eletrônico: jussaramaria.mendes@gmail.com 
Daniela Trevisan Monteiro, Cristine Gabrielle da Costa dos Reis, Alberto Manuel Quintana, Jussara Maria Rosa Mendes

Recebido em: 09/10/2014

Reformulado em: 20/04/2015

Aceito para publicação em: 22/04/2015

\section{Notas}

* Psicóloga. Mestre em Psicologia. Doutoranda do programa de Pós-Graduação em Psicologia Social e Institucional pela Universidade Federal do Rio Grande do Sul, bolsista CAPES.

** Psicóloga, Mestranda do Programa de Pós-graduação em Psicologia da Universidade Federal de Santa Maria e bolsista CAPES.

*** Psicólogo, Doutor em Antropologia Clínica, Pós-doutor em Bioética pela Universidad Complutense de Madrid. Professor Titular do Curso de Psicologia e do Programa de Pós-Graduação em Psicologia da Universidade Federal de Santa Maria. **** Assistente Social, Doutora em Serviço Social, Pós-doutora em Serviço Social pela Universität Kassel, República Federal da Alemanha (2010). Docente credenciada a Pós-Graduação em Psicologia Social e Institucional do Instituto de Psicologia/ UFRGS, colaboradora do Programa de Pós Graduação em Serviço Social da PUCRS, professora adjunto do curso de Serviço Social da UFRGS. 